\title{
Occurrence of black leaf spot caused by Alternaria alternata on Korla fragrant pear in Xinjiang of China
}

\author{
Xiaofei Chen ${ }^{1}\left(\mathbb{D} \cdot\right.$ Liping Teng $^{1} \cdot$ Hongxia Dan ${ }^{1} \cdot$ Renci Xiong ${ }^{1}$ \\ Received: 28 February 2019 / Accepted: 3 September 2019/Published online: 16 October 2019 \\ (C) Società Italiana di Patologia Vegetale (S.I.Pa.V.) 2019
}

Keywords Korla fragrant pear $\cdot$ Alternaria alternata black leaf spot

In September 2017, leaf spot and necrosis were observed on Korla fragrant pear in Xinjiang Alaer area, with an approximated incidence of 10-30\%. Symptoms appeared as circular black spots, and some spots coalesced into irregular necrotic patches. The severely affected trees were defoliated finally. The pathogen was isolated from portions of surfacesterilized diseased leaves incubated on potato dextrose agar (PDA) at $27^{\circ} \mathrm{C}$ for 7 days. Colonies were dark olive color, with loose, cottony aerial mycelia on the surface of cultures. On potato carrot agar (PCA), conidiophores were septate, straight or curved, short to long, simple or branched, and with one or several apical conidiogenous loci. Conidia were ellipsoid or obpyriform, golden brown in color, 16.4 to 30.6 (average, 20.7) $\mu \mathrm{m}$ long and 5.3 to 11.8 (average, 8.2) $\mu \mathrm{m}$ wide with zero to two longitudinal and one or more transverse septa. Each conidia had a short to long beak. For further identification, partial sequences of ribosomal internal transcribed spacer (ITS), endopolygalacturonase (endoPG) and histone H3 (HIS3) were generated with the primer pair ITS1/ITS4 (White et al. 1990), PG2b/PG3a (Andrew et al. 2009) and H3-1a/h3-1b (Glass and Donaldson 1995), then deposited in GenBank (MG744379 for ITS, MK044899 for endoPG, MG744388 for HIS3). BLAST analysis revealed that the ITS and endoPG sequences had 99\% similarity with A. alternata (KP124372.1, KP124076.1), the HIS3 sequences shared $100 \%$ similarity with A. alternata (MK085979.1).
Based on morphology characteristic and phylogenetic analysis, the fungal isolate was identified as A. alternata (Simmons 2007). Pathogenicity test was performed by inoculating with a $10-\mu 1$ droplet of conidia suspension $\left(1 \times 10^{6}\right.$ spores $\left./ \mathrm{ml}\right)$ on 8 detached leaves with three replications. Both inoculated and control (sterilized water) leaves were stored at $27{ }^{\circ} \mathrm{C}$. The same symptoms seen in the field were observed after 7 days by inoculated plants only, and A. alternata was reisolated from the inoculated leaves. To our knowledge, this is the first report of black leaf spot disease caused by A. alternata on Korla fragrant pear in Xinjiang.

\section{References}

Andrew M, Peever TL, Pryor BM (2009) An expanded multilocus phylogeny does not resolve morphological species within the smallspored Alternaria species complex. Mycologia 101:95-109

Glass NL, Donaldson GC (1995) Development of primer sets designed for use with the PCR to amplify conserved genes from filamentous ascomycetes. Appl Environ Microbiol 61:1323

Simmons EG (2007) Alternaria: an identification manual. CBS, Fungal Biodiversity Center Utrecht, The Netherlands

White TJ, Bruns T, Taylor J (1990) PCR protocols: a guide to methods and applications. Academic Press, San Diego

Publisher's note Springer Nature remains neutral with regard to jurisdictional claims in published maps and institutional affiliations.

Xiaofei Chen

cxfzky@126.com

1 College of Plant Science, Tarim University, Xinjiang Alaer, China 